\title{
Influence of pipe hangers on creep damage of Main-Steam Pipe Containing Defects
}

\author{
Zhangwei Ling \\ Zhejiang Provincial Special Equipment Inspection and \\ Research Institute \\ Hangzhou, 310020, P. R. China \\ lingzhangwei@163.com
}

Min Wang

Zhejiang Provincial Special Equipment Inspection and Research Institute

Hangzhou, 310020, P. R. China

wangmin@nbu.edu.cn

\author{
Weiyong Cai \\ Zhejiang Provincial Special Equipment Inspection and \\ Research Institute \\ Hangzhou, 310020, P. R. China \\ cwy831@126.com \\ Ping Tang \\ Zhejiang Provincial Special Equipment Inspection and \\ Research Institute \\ Hangzhou, 310020, P. R. China \\ tangpingjob@163.com
}

\begin{abstract}
The pipe hanger is an important part of steam pipeline system in power plant. In order to study the influence of pipe hangers on creep damage of main-steam pipe containing defects. In the paper, the main-steam pipe with defects was taken as the research objects. The pipe analysis model with pipe hanger was established. Based on the creep damage mechanics, the influence of distance and arrangement of pipe hanger constraints was studied, and the effects of creep stress at pipe defects were given. The results show that the pipe hanger can greatly influence the creep stress distribution of pipe. With the decreasing of pipe hanger distance between the defect, the stress intensity increased. The creep stress of defect were also researched under different type of pipe hanger, and the fixed constraint hanger has the maximum stress. The results can give the constructive suggestion for the engineering design of the arrangement of pipe hanger.
\end{abstract}

Keywords-main-steam pipe; pipe support and hanger; creep; defects; damage

\section{INTRODUCTION}

The pipe support and hanger is an important part of steam pipeline system in power plant, having the functions of bearing piping loads, constraining displacement reasonably, increasing the stability and preventing vibration of pipe. With the rapid development of power industry, according to statistics, the power production safety accidents caused due to the failure of pipe support and hanger is particularly prominent[1-4]. The failure of pipe support and hanger inevitably will change the load distribution, and the unreasonable stress distribution will speed up the damage of pipe creep stress, shorten the life of pipeline and bring significant security risks to the safe operation of the pipeline, thereby affecting the safety and reliability of the entire power plant production[5-6]. Therefore, it is very necessary to study the creep damage of pipeline with defects affected by the pipe support and hanger, which also is an important way to improve safety and reliability of power plant production.

\section{CReEP DAMAGE MeChanics}

Generally considered, the creep process include the hardening and creep damage mechanism[7-10], i.e.

$$
\varepsilon_{c}=\varepsilon_{c}^{h}+\varepsilon_{c}^{d}
$$

Where, $\varepsilon_{c}^{h}$ is the hardening creep strain; $\varepsilon_{c}^{d}$ is the damage creep strain.

Norton-Bailey model, taking a time-hardening creep model and according to the initial conditions[11], having,

$$
\varepsilon_{c}^{h}=A_{1} \sigma_{e}^{n} t^{m} e^{-\frac{Q}{R T}}
$$

Where, $A_{1}$ is the material constant, $\mathrm{n}$ is the stress exponent, and $\mathrm{m}$ is the time-hardening exponent.

Kachanov-Robatnov damage theory[11], which describe the creep damage evolution based on Norton creep constitutive equation as,

$$
\dot{D}=\left[\frac{\sigma}{A(1-D)}\right]^{K}
$$

Where, $\sigma$ is the holding stress in the creep test; A, K are material constants; $\mathrm{D}$ is the damage factor.

And, based on the Norton creep model and damage factor $\mathrm{D}[11]$, have,

$$
\varepsilon_{c}^{d}=A_{2} \cdot \sigma^{\omega} \cdot\left(1-\left(1-\frac{t}{t_{R}}\right)^{\theta}\right)
$$


Where, $\mathrm{r}$ and $\mathrm{q}$ are material constants; ${ }_{R}$ is rupture time, $t_{R}$ is rupture time, $\frac{t}{t_{R}}$ is life-fraction, $A_{2}=\frac{k \cdot t_{R}}{\theta}$, $\theta=1-\omega /(r+q+1)$.

Thus, based on Norton-Bailey law and creep damage model, the combined creep damage model is given as[11],

$$
\begin{aligned}
& \varepsilon_{c}=\varepsilon_{c}^{h}+\varepsilon_{c}^{d} \\
& =A_{1} \sigma_{e}^{n} t^{m} e^{-\frac{Q}{R T}}+A_{2} \sigma_{e}^{\omega}\left(1-\left(1-\frac{t}{t_{R}}\right)^{\theta}\right)
\end{aligned}
$$

\section{NUMERICAL ANALYSIS MODEL}

According to the function type, the pipe support and hanger has type of guiding support, bearing load and limiting displacement. The different boundary conditions or centralized constraint force will be applied to the pipe for the different pipe support and hanger type. The paper takes the main-steam pipe with defects and under the conditions of high temperature and high pressure as the research object, and has establish the analysis model for creep damage of pipe and analysis the creep stress of pipe defects.

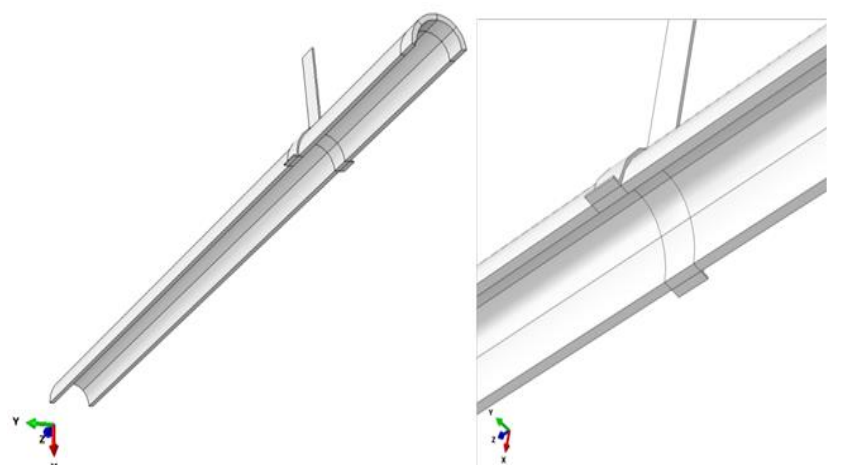

Figure 1. Structural model

The numerical model of pipe as shown in Fig .1, the external diameter is $165 \mathrm{~mm}$, the thickness is $30 \mathrm{~mm}$, the length of pipe is $5000 \mathrm{~mm}$. The half of pipe structure is taken into account since the symmetry of pipe structure, defects shape and load bearing. The volumetric defect located at the inner wall of pipeline, has the radius of $15 \mathrm{~mm}$, as shown in Fig .1. The pipe material is P91 steel, having $\mathrm{E}=165 \mathrm{GPa}, \mathrm{v}=0.3, \sigma \mathrm{y}=200 \mathrm{MPa}$ at the temperature of $625^{\circ} \mathrm{C}$. The time-hardening creep model mentioned above was adopted, which the material constants determined by experiment[11]. The pressure load of $10 \mathrm{MPa}$ was applied to the inner pipe wall and the corresponding axial force was applied to the cross-section of pipe. The pipe was meshed as Fig .2.

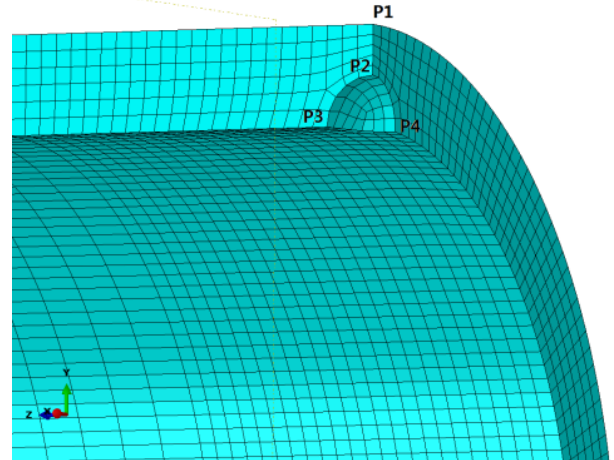

Figure 2. The mesh grid

\section{A. The distance of hanger}

The fixed constrains type of pipe support and hanger was considered when numerical simulate the effect of distance of pipe support and hanger. The distance of pipe support and hanger apart from left side is $500 \mathrm{~mm}$, $1200 \mathrm{~mm}, 2700 \mathrm{~mm}, 3600 \mathrm{~mm}$.

\section{B. The type of pipe support and hanger}

And, the three types of pipe support and hanger was considered, respectively with the function of the fixed, rigid and limiting displacement. The fixed constraint of pipe support and hanger has the limitation of $\mathrm{U} 1=\mathrm{U} 2=\mathrm{U} 3=\mathrm{UR} 1=\mathrm{UR} 2=\mathrm{UR} 3=0$ at the contact surface of pipe and pipe support and hanger. The rigid hanger bears the weight of pipeline and constrains the vertical displacement, for which the gravitational field with $\mathrm{g}=9800 \mathrm{~mm} / \mathrm{s}^{2}$ was applied. The limiting displacement of hanger without bearing the weight of pipeline, limits the linear or angular displacement of one direction. In the analysis model, the X,Y and UR1 was limited.

\section{RESULTS}

\section{A. Creep damage for the distance of hanger}

Based on the results of analysis model, the creep stress of pipe with the distance of $3600 \mathrm{~mm}$ and the creep time of $3 \mathrm{e} 7 \mathrm{~s}$ is shown in the Fig .3.

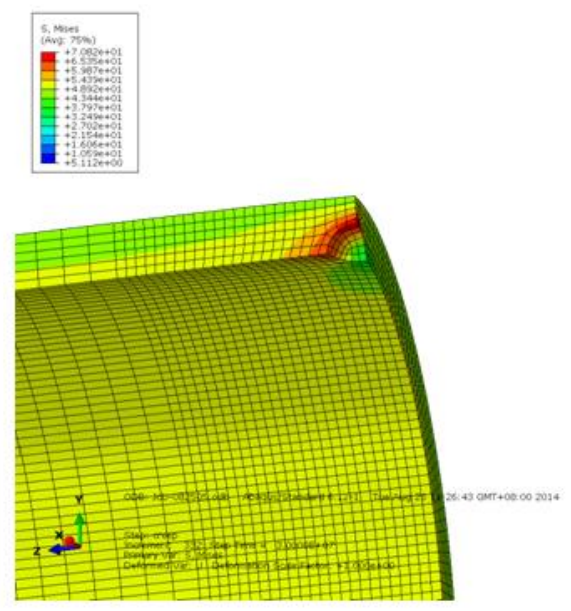

Figure 3. The creep stress with time of $3 \mathrm{e} 7 \mathrm{~s}$ and distance of $3600 \mathrm{~mm}$ 
As shown in the Fig .3, the creep stress of inner wall is higher than that of outer wall of pipe, because of the function of inertial pressure, and the volumetric defect has stress concentration. And the stress concentrated obviously during the feature point of P2 and P3 at defect. The Fig .4 gives the creep stress distribution of the edge node around defect under different distance, showing that there are two stress peak corresponding to the P2 and P3, because of the geometric imperfections.

The Fig .4 also shows that the creep stress with the distance of $500 \mathrm{~mm}$ is less than that of others, because of the Saint-Venant's Principle, for the hanger constrains with higher distance to defect will take less effect to the stress of defect. With the increase of distance, i.e., the constrain will be closer to the defect, the creep stress will be increased and the obviously at P2. And since the P2 has the minimum distance to the outer wall of pipeline, the P2 will be the relative weakness of pipeline defect.

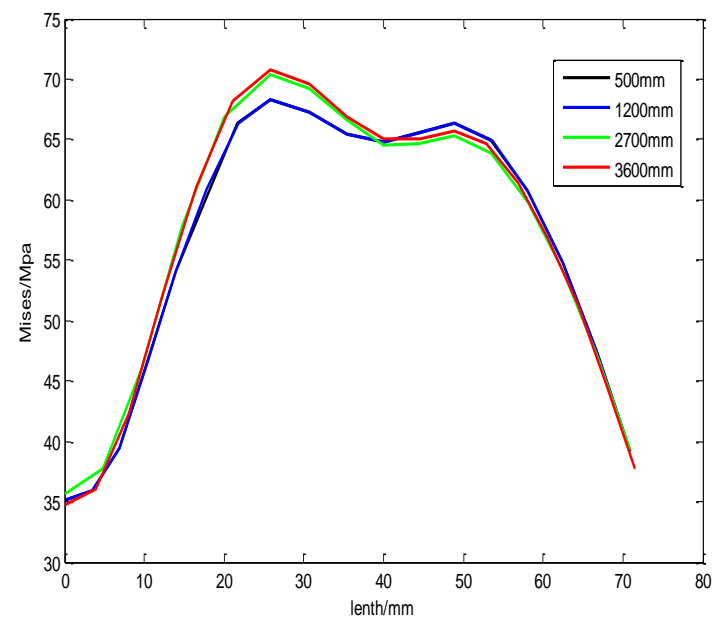

Figure 4. The creep stress distribution of the edge node around defect under different distance

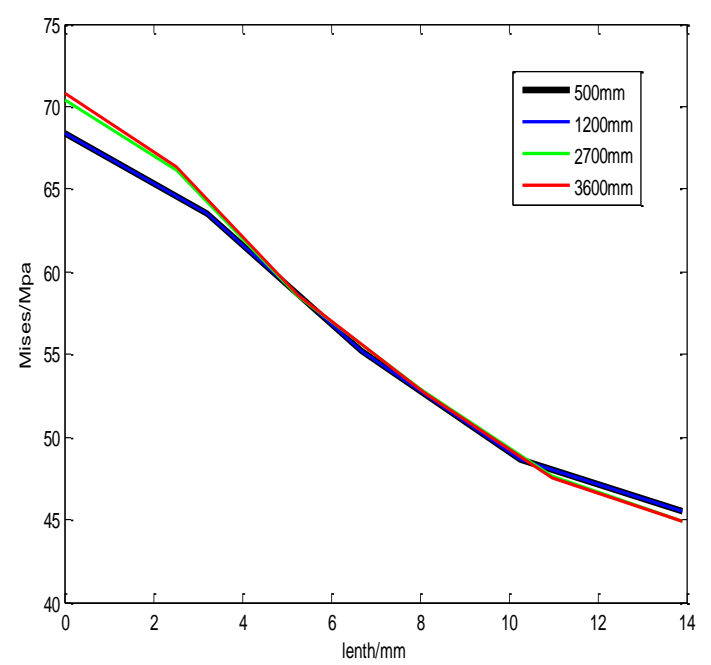

Figure 5. The creep stress distribution in thickness direction

The Fig .5 shows the creep stress distribution in the thickness direction, along the line of $\mathrm{P} 2$ to $\mathrm{P} 1$. As results shows, the creep stress decreased with the direction to outer wall, because of the internal pressure and geometric imperfections. And also, with the increase of distance of hanger, the stress of inner wall increased while the outer wall stress decreased, because the cross section bending moment are different since the different distance of constraints.

The Fig .6 shows the equivalent ceep strain of feature point at defect with the distance of pipe support and hanger to left side is $2700 \mathrm{~mm}$. The creep strain has slowly increased with the increase of creep time and the ramping rate gets smaller. And as shown in Fig .6, the creep strain of Point P2 is the maximum, because of the creep stress of the structure and the volumetric defect.

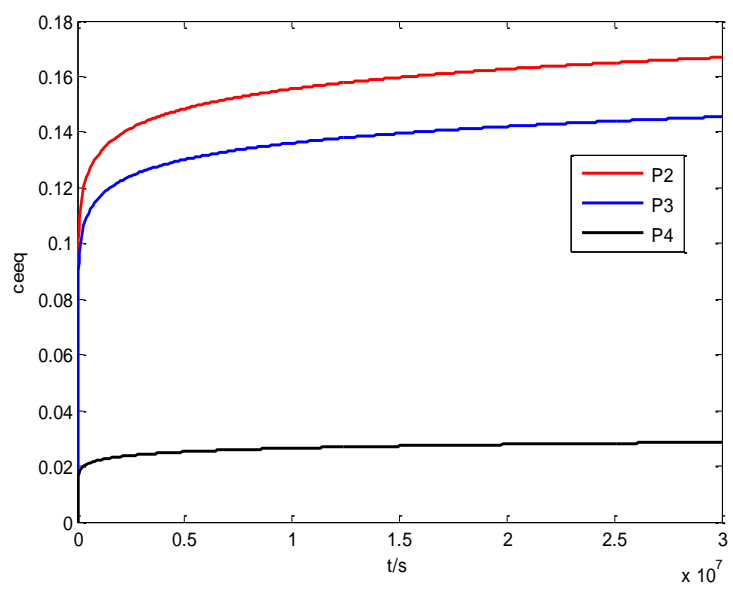

Figure 6. The creep strain of feature point

\section{B. Creep damage for the constrains type of pipe support and hanger}

For the three type of constraints model, the results, shown as Fig .7, indicating that the different pipe support and hanger will has different creep stress along the direction of thickness. The fixed constrains has the maximum stress performance since the constraint limits the all linear and angular displacement of contact surface which having more constraint condition compared to other constraints.

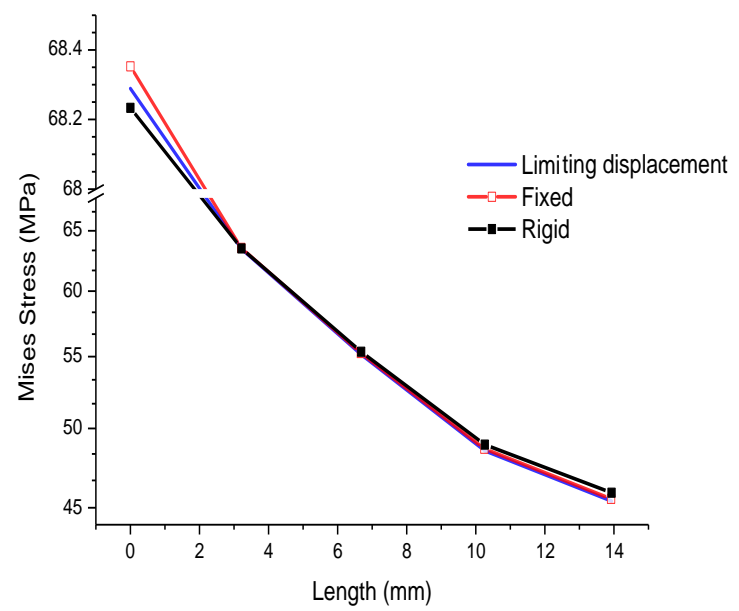

Figure 7. The creep stress distribution in the thickness direction with creep time of $3 \mathrm{e} 7 \mathrm{~s}$ 
The Fig.8 shows the creep stress distribution of the edge node around defect under different constraints of pipe support and hanger. With the increase of constraint condition, the variation of creep stress at feature point $\mathrm{P} 2$ is different from the point $\mathrm{P} 3$, because of the limitation of constrains are applied to the contact surface of pipeline and pipe support and hanger.

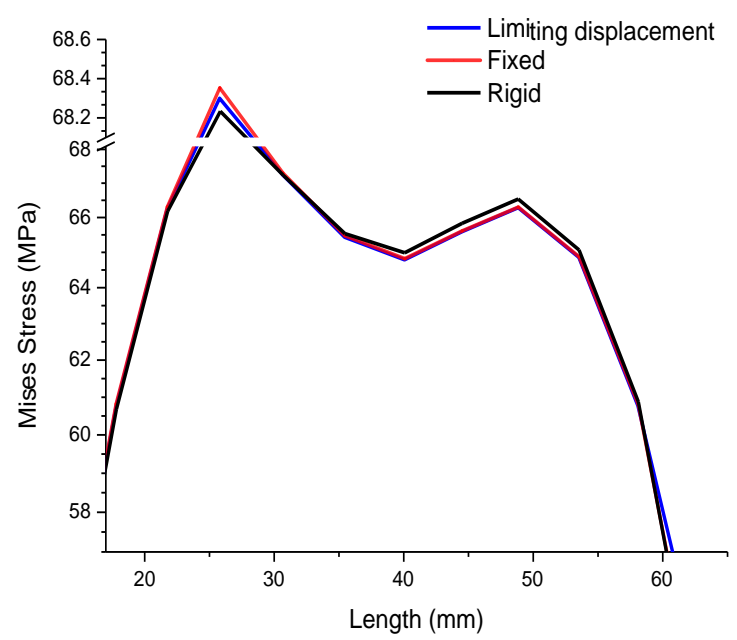

Figure 8. The creep stress distribution of the edge node around defect under different constraints with time of $3 \mathrm{e} 7 \mathrm{~s}$

\section{CONCLUSIONS}

The paper takes the main-steam pipe with defects and under the conditions of high temperature and high pressure as the research objects, and has established the analysis model for creep damage of pipe. Combined with the creep damage mechanics, the distance and arrangement of pipe support and hanger constraints has been studied for the effect of creep stress of pipe, then, obtains,

- The pipe support and hanger will influence the creep stress distribution of pipe and the defect has high stress concentration. With the decreasing distance of pipe support and hanger to defect, the stress intensity will be increased, particularly at the feature point.

- For the different type of pipe support and hanger, with the increase of constraints condition applied to pipeline, the creep stress of defect showing a rising trend, and the fixed constraint hanger has the maximum stress performance.

- During the engineering arrangement of pipe support and hanger, the principle of anchoring the bracket as little as possible should be followed and should reduce the welding work. Moreover, the deformation and the stress of pipe under pressure and thermal load should also be considered, then the position of pipe support and hanger and restraint can be adjusted based on the deformed and stress of pipeline.

\section{ACKNOWLEDGMENT}

This project is supported by the Major Project of Zhejiang Bureau of Quality and Technical Supervision(NO. 20110106 ).

\section{REFERENCES}

[1] M. Chen, H. ZH. Zhou, "Study on Support and Hanger Layout of Complex Piping Stress Analysis",China Academic Journal Electronic Publishing House,Mar,2009,pp.21 25,doi:103969/.jissn.1001-4837.2009.03.005

[2] Y. G. Liu, Q. L. Zhang, "Steam-water Pipes Design and Notice",Value Engineering,vol.19,2010,pp:83-84,doi: 10.14018/j.cnki.cn13-1085/n.2010.19.025

[3] L. Yu, ZH. Zhao, "The Design and Application of Support and Hanger at Low Temperature Piping",Development and Innovation of Machinery and Electrical Products,May,2014,pp:4-6,doi: 10.3969/j.issn.1002-6673.2014.05.002.

[4] B. Z. Qin, K. H. Huang and Q. ZH. Xiao, "Cause Analysis on Suspender Breakage of Constant Force Hanger for Lowtemperature Reheating Steam Piping in 600 MW Units in a Fossilfuel Power Plant and the Solutions",Guangdong Electric Power,vol.25,Mar,2012,pp:109-113,doi:1007-290X(2012)03-010905 .

[5] T. X. Ci,"Measures of Pipeline Support Suspended Frame Increasing Span ", Shanxi Architechure, vol.38,Aug,2012,pp:126127,doi: 10.13719/j.cnki.cn14-1279/tu.2012.22.058.

[6] H. An, L. F. An, H. G. Han and M. J. Wang, "Common Problems and Case Study for Pipe Support and Hangers in Power Generating Units",China Academic Journal Electronic Publishing House,Nov,2012,pp:80-82,doi:10.3969/j.issn.10023364.2012.11.080

[7] A. Zolochevsky, A. Martynenko , A. Kühhorn, "Structural benchmark creep and creep damage testing for finite element analysis with material tension-compression asymmetry and symmetry". Computers and Structures, vol. 100-101, Mar. 2012, pp. 27-38, doi:10.1016/j.compstruc.2012.02.021.

[8] L. Esposito, N. Bonora, "A primary creep model for Class M materials". Materials Science and Engineering A, vol. 528, Mar. 2011, pp.5496-5501, doi:10.1016/j.msea.2011.03.069.

[9] N. Aleš, K. Ladislav, U. Boris, "Uni-axial and multi-axial creep behavior of P91-type steel under constant load". Engineering Failure Analysis, vol. 18, Mar. 2011, pp. 61-67. doi:10.1016/j.engfailanal.2010.08.005.

[10] T.H. Hyde, M. Saber, W. Sun, "Creep crack growth data and prediction for a $\mathrm{P} 91$ weld at $650^{\circ} \mathrm{C}$ ", International Journal of Pressure Vessels and Piping, vol. 87, 2010, pp.721-729, doi:10.1016/j.ijpvp.2010.09.002

[11] F.J. Liu, P. Tang, S. Kong, "Investigations on creep behavior of p91-type steel using combined creep damage model", 2013 ASME Pressure Vessels and Piping Division Conference, Jul. 2013, pp.1418, Paris, France. 